\title{
Studies of intestinal lymphoid tissue. VI-Proliferative response of small intestinal epithelial lymphocytes distinguishes gluten- from non-gluten-induced enteropathy
}

\author{
MICHAEL N MARSH, MANSEL R HAENEY
}

From the Departments of Medicine and Clinical Immunology, Hope Hospital (University of Manchester School of Medicine), Salford, Manchester

SUMMARY Several diseases of the small intestine, including gluten-sensitivity, present with malabsorption and a "flat" mucosa. Determination of the mitotic index of epithelial lymphocytes provides a simple, objective method of assessing, and thus of predicting, whether a flat mucosa is due to gluten-sensitivity (index $>0.2 \%$ ), or not (index $<0.2 \%$ ).

The use of this index in circumstances especially likely to cause diagnostic confusion-for example, intestinal lymphoma; Crohn's jejunitis of immunodeficiency-is illustrated in this paper. Of seven cases, five (two primary lymphoma, three immunodeficiency) had been treated with a gluten-free diet without benefit; a mitotic index performed on the initial biopsy in each of these patients could have predicted from the outset that none was gluten-sensitive. Of the remaining two cases, determination of the mitotic index on the biopsy initially obtained from a man with severe hypogammaglobulinaemia would have indicated that he was also gluten-sensitive. Empirical use of a gluten-free diet was avoided in the other patient (with flat small intestinal mucosa and low mitotic index) in whom the diagnosis was ultimately shown to be due to Crohn's disease of jejunum.

The primary underlying cause of coeliac disease is unknown ${ }^{1-3}$ although its diagnosis requires $(i)$ the presence of a severe lesion of the upper intestinal mucosa which (ii) improves on gluten withdrawal. ${ }^{4-6}$ Villous flattening is not exclusive to coeliac disease, however, since similar mucosal reactions have been documented in over thirty other clinical and experimental conditions. ${ }^{7}$ Clearly, then, the demonstration of mucosal improvement on a glutenfree diet with regeneration of intestinal villi becomes a vital, if somewhat retrospective, diagnostic criterion.

In practice, however, the diagnosis may not always be clear-cut. For example, there are many patients who, despite excellent symptomatic, haematological and biochemical responses to strict gluten withdrawal, fail to regenerate villi. In some cases, there is evidence of previous mucosal responsiveness that is subsequently lost after unsuspected exposure to gluten, ${ }^{89}$ suggesting that failure of regeneration

Accepted for publication 16 July 1982 could be due to mechanisms other than gluten ingestion.

Neither is the diagnosis always clarified by the use of gluten-challenge as an additional means of demonstrating sensitivity. ${ }^{10}$ This kind of approach demands repeated biopsies of jejunal mucosa; it lacks agreed uniformity of practice as to what quantity of bread, crude gluten or its fractions constitutes a standard challenge and what is the optimal timing for repeat biopsy in order to show maximal effect. ${ }^{12-14}$ Relapses, both in children ${ }^{15}$ and especially in adults ${ }^{16}$ may take weeks or even months to become apparent, while conversely, the "tolerance" of other patients to continued gluten ingestion ${ }^{17} 18$ conflicts with the immediate appeal of gluten challenge as an incisive, short-term aid to diagnosis.

If coeliac disease is due to a local immunological reaction to gluten, then the mucosa might be expected to reflect that reaction. In recent studies ${ }^{19}$ it was shown that the epithelial lymphocyte population of mucosal biopsies from untreated coeliac patients possesses approximately $6 \%$ more immunoblasts, and a much higher basal mitotic index $(\gg 0.2 \%)$ 
compared with control mucosae; these differences were reversed on a gluten-free diet. ${ }^{20}$ Studies of other intestinal diseases, many of which were associated with villous flattening, confirmed that a high mitotic index among epithelial lymphocytes is exclusive to coeliac disease ${ }^{21}$ thus allowing all coeliac patients to be identified prospectively on their initial, pretreatment biopsy. ${ }^{22}$

In this paper, we draw attention to the value of the mitotic index of epithelial lymphocytes in circumstances where the distinction between gluten- and non-gluten-induced "flat" jejunal lesions associated with malabsorption often causes diagnostic problems. The case studies illustrate (i) that confident decisions as to whether gluten-sensitivity exists are possible on a single (flat) biopsy without need of any specialised histological technique; (ii) that gluten-sensitivity may be identified even when associated with another cause of villous flattening, and (iii) that a "trial" of gluten-free diet may thus be avoided in any patient predicted from the outset, not to be gluten-sensitive.

\section{Patients, material and methods}

Of the seven patients included in this study, six were seen in the University Department of Medicine at Hope Hospital between 1975 and 1980. All had features of malabsorption, a "flat" jejunal mucosa obtained by peroral biopsy with a Watson capsule and with one exception (case 1), had received a glutenfree diet at some stage during their illness. The remaining patient (case 7) was seen at Northwick Park Hospital; permission to include his history was given by Dr ADB Webster, and histological material was kindly provided by Dr G Slavin.

Specimens of jejunal mucosa were processed in paraffin wax, sectioned at a thickness of $5 \mu \mathrm{m}$ and stained with haematoxylin and eosin. All specimens were reviewed "blindly" by one of us (MNM) without knowledge of diagnosis, or where this was not possible, of the relation of the several biopsies to periods of gluten restriction.

Mitotic indices were calculated by determining the percentage mitotic figures (metaphases) in a population of 3000 epithelial lymphocytes per specimen, as described elsewhere. ${ }^{22}{ }^{23}$ It is important to stress that counting was restricted to epithelium interspersed between adjacent crypt mouths, so as to avoid crypt cell mitoses which are frequently present around the luminal aspect of the crypt mouth. No specimen was reviewed, or its mitotic index modified, once the clinical diagnosis or sequence of biopsies relevant to the course of each patient's illness, was revealed. All details are included in the Table.

\section{Case reports}

CASE 1: SCHOOLBOY AGED 16 YR

This youth presented with a short history of abdominal discomfort, nausea, and diarrhoea up to five times daily with soft motions difficult to flush away.

On examination he was pale and thin, without secondary sexual development. His height was 166 cm (25-50 percentile) and weight $45 \mathrm{~kg}$ (3-10 percentile). Investigations revealed the following results: haemoglobin $10.3 \mathrm{~g} / \mathrm{dl}$; white cell count 6.3 (neutrophils $60 \%$, lymphocytes $20 \%$, monocytes $17 \%$ and eosinophils 1\%); MCV $60 \mathrm{fl}$, ESR $25 \mathrm{~mm} / \mathrm{h}$; serum folate $0 \cdot 2 \mathrm{ng} / \mathrm{l}$ (normal 2-13); $\mathrm{B}_{12} 280 \mathrm{ng} / \mathrm{l}$ (normal $160-950$ ); red cell folate $85 \mathrm{ng} / \mathrm{ml}$ (normal $>120$ ); serum iron $2.5 \mathrm{mmol} / \mathrm{l}$ (normal 10-32); albumin $33 \mathrm{~g} / \mathrm{l}$ and globulin $26 \mathrm{~g} / \mathrm{l} ; \mathrm{Ca}^{++} 2 \cdot 12 \mathrm{mmol} / \mathrm{l}$; phosphorus $1.25 \mathrm{mmol} / \mathrm{l}$; alkaline phosphatase $85 \mathrm{IU} / \mathrm{L}$ (normal $<93$ ). Serum immunoglobulins were normal, but

Table

\begin{tabular}{|c|c|c|c|c|c|}
\hline Case no & Mucosal histology & Figure & $\begin{array}{l}\text { Mitotic index } \\
\text { (normal } \\
<0 \cdot 2 \% \text { ) }\end{array}$ & Diagnosis & $\begin{array}{l}\text { Relation of biopsy to } \\
\text { gluten-free diet }(G F D)\end{array}$ \\
\hline $\begin{array}{l}4 \\
5 \\
6 \\
7\end{array}$ & $\begin{array}{l}\text { Flat } \\
\text { Flat } \\
\text { (i) Flat } \\
\text { (ii) Flat } \\
\text { (iii) Flat } \\
\text { (iv) Flat } \\
\text { Flat } \\
\text { Flat } \\
\text { Flat } \\
\text { Flat } \\
\text { Partial villous regeneration } \\
\text { Partial villous regeneration } \\
\text { Flat }\end{array}$ & $\begin{array}{l}1 \\
2 \\
3 \\
3 \\
3 \\
\frac{4}{-} \\
- \\
5 \\
-\end{array}$ & $\begin{array}{l}0 \cdot 1 \\
\text { zero } \\
0 \cdot 1 \\
0 \cdot 1 \\
0 \cdot 1 \\
0 \cdot 1 \\
\text { zero } \\
0 \cdot 1 \\
\text { zero } \\
0 \cdot 42 \\
0 \cdot 1 \\
0 \cdot 1 \\
0 \cdot 67\end{array}$ & $\begin{array}{l}\text { Diffuse Crohn's jejunitis } \\
\text { Centrocytic lymphoma } \\
\text { Malignant histiocytic lymphoma } \\
\text { Hypogammaglobulinaemia } \\
\text { Hypogammaglobulinaemia } \\
\text { Hypogammaglobulinaemia } \\
\text { Hypogammaglobulinaemia and } \\
\text { coeliac disease }\end{array}$ & $\begin{array}{l}\text { Not given } \\
\text { Before GFD } \\
\text { Laparotomy (1961) } \\
\text { Before GFD (1976) } \\
\text { Six months after GFD (1976) } \\
\text { At laparotomy (1977) } \\
\text { Before GFD } \\
\text { Before GFD } \\
\text { Before GFD } \\
\text { Before GFD } \\
\text { Six months after GFD } \\
\text { After gluten “challenge “- } \\
2 \text { yr later } \\
\text { Three months later after normal } \\
\text { diet }\end{array}$ \\
\hline
\end{tabular}


reticulin antibody was positive.

Tests of intestinal function revealed normal xylose absorption $(1.8 \mathrm{~g} / 5 \mathrm{~h}$ after $5 \mathrm{~g}$ oral dose; normal $>1 \cdot 2$ $\mathrm{g}$ ); but mild steatorrhoea (faecal fat excretion 8 g/24 h; normal < 6).

Barium follow-through showed a diffuse abnormality of upper small bowel and jejunal biopsy revealed patchy change, including areas of complete villous flattening with reduced epithelial cell height (Fig. 1).

\section{Comment}

The presence of severe iron and "folate" deficiency, hypoalbuminaemia, steatorrhoea, positive reticulin antibody and abnormal small bowel radiology suggested a malabsorption syndrome secondary to coeliac disease, Crohn's disease or lymphoma; the latter was excluded on mucosal histology. The mitotic index of $0.1 \%$ (normal $<0.2 \%$ ) among epithelial lymphocytes (Table) was well below that expected in untreated coeliac disease and thus argued against this diagnosis and hence against the need for a therapeutic trial of a gluten-free diet. He was the first patient in our Department in whom a positive decision not to treat with a GFD was made on the basis of a low mitotic index. Indeed, a further review of additional sections of jejunal mucosa (by Department of Histopathology) revealed presence of non-caseating granulomas: his subsequent course over the next two years was one of repeated episodes of watery diarrhoea, attacks of severe colicky abdominal pain and a perianal abscess, consistent with a final diagnosis of Crohn's disease.

\section{CASE 2: TIMBER YARD MANAGER, AGED 52 YR}

This man complained of general ill health, alcoholinduced epigastric discomfort and watery diarrhoea, without blood or mucus. There was no previous illness or gastrointestinal disturbance. On examination, there was slight upper abdominal tenderness with mild ascites and ankle oedema. His weight was $73 \mathrm{~kg}$. Investigations included a haemoglobin of $13.6 \mathrm{~g} / \mathrm{dl}$ and a serum albumin of $26 \mathrm{~g} / \mathrm{l}$. He was thought to have liver disease and was treated with diuretics. However, one month later, his weight had fallen a further $2 \mathrm{~kg}$ despite worsening of the oedema, and his diarrhoea had increased considerably. There was also weakness of the right hand, without wasting, fasciculation or

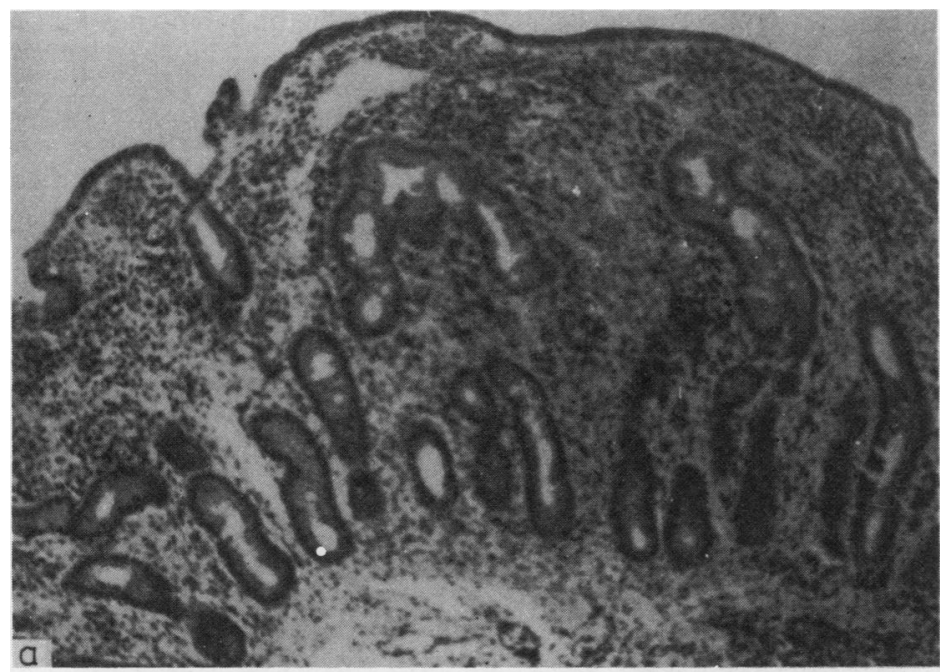

Fig. 1 (a) Completely flat mucosa (Crohn's jejunitis) showing crypt hypertrophy and reduced epithelial cell height (Magnification approx $\times 70$ ). (b) Detail of epithelium shows small lymphocytes and a polymorph leucocyte: mitotic activity of epithelial lymphocytes was normal. $\times 820$.

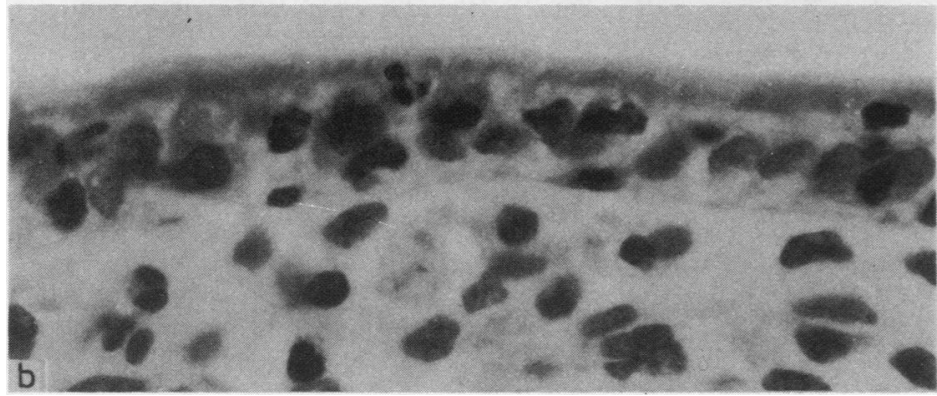


sensory loss. He was admitted to exclude neoplasm associated with peripheral neuropathy and proteinlosing enteropathy. On admission, his weight was now $66 \mathrm{~kg}$ and cutaneous pigmentation was present.

Investigations revealed severe nutritional deficiencies, with a serum iron of $5 \mathrm{mmol} / \mathrm{l}$ (normal 10-32), hypoalbuminaemia and hypogammaglobulinaemia; a flat glucose tolerance curve (maximum rise $2 \mathrm{mmol} / \mathrm{l})$, and gross steatorrhoea $(42 \mathrm{~g} / 24 \mathrm{~h}$; normal <6). A jejunal biopsy was "flat" when viewed under the dissecting microscope and a presumptive diagnosis of coeliac disease was made (Fig. 2). He was started immediately on a gluten-free diet together with nutritional supplement, Parentrovite and Lomotil (diphenoxylate). Despite this treatment, his diarrhoea became profuse and persistent, and was accompanied by much abdominal pain. Histological examination of the jejunal mucosa revealed diffuse, undifferentiated lymphoma of centrocytic type, and his therapy was therefore changed to intravenous vincristine, oral cyclophosphamide and prednisolone, together with an elemental diet.

Within a month he developed weakness of the right arm, numbness of the right hand side of the face and dysphasia. Brain scan revealed marked cerebral atrophy, but no localising lesion; cerebrospinal fluid was clear. Because of the leucopenia, treatment was further modified to chlorambucil and steroids which resulted in gradual improvement of intestinal and cerebral symptoms.

Three months later, abdominal symptoms again worsened and his weight was now $15 \mathrm{~kg}$ below that at presentation. Episodes of intestinal obstruction required laparotomy which showed multiple haemorrhagic obstructions throughout the jejunum and upper ileum. Despite further chemotherapy and parenteral feeding he rapidly deteriorated and died about one year after initial presentation. Post- $\stackrel{\text { 을 }}{\text {. }}$ mortem examination did not reveal any new findings, $\overrightarrow{\vec{F}}$ and section of the fixed brain showed no apparent $\stackrel{9}{\rightarrow}$ histological abnormality.

\section{Comment}

This man was found to have a "flat" jejunal mucosa with severe malabsorption and presumed proteinlosing enteropathy. He was initially thought to have coeliac disease and treated appropriately but the gluten-free diet had no effect on his diarrhoea in the short-term. Once lymphoma was diagnosed, inten- 용 sive chemotherapy was started but this did little to $\omega$ halt the progression of the lymphoma. His cerebral in lesion was probably due to multifocal leucoencephalopathy, rather than to a coeliac-associated $\overrightarrow{0}$ cerebral syndrome. ${ }^{24}$

His jejunal biopsy, although flat (Fig. 2) showed no mitotic activity among epithelial lymphocytes 7 (mitotic index $=$ zero), despite the obvious proliferative aggressiveness of the infiltrating tumour. These observations indicate that the lymphoma was a primary lesion, and not secondary to gluten-sensitive $\overrightarrow{0}$ enteropathy, the latter complication being more $\stackrel{\infty}{\infty}$ usually associated with histiocytic, rather than lymphocytic, tumours. Clearly, he had no need for a gluten-free diet.

\section{CASE 3: SCHOOL CARETAKER, AGED 41 YR}

For five years before referral, this man had $\overline{\vec{O}}$ complained of regular attacks of abdominal pain 3 associated with vomiting and $4 \mathrm{~kg}$ weight loss. On examination, he was weak, pale and thin, the liver was palpable $5 \mathrm{~cm}$ below the right costal margin. $\mathrm{He}$ 응 was thought to have a duodenal ulcer responsive to $:$ bed rest and a milk drip. However during the next few

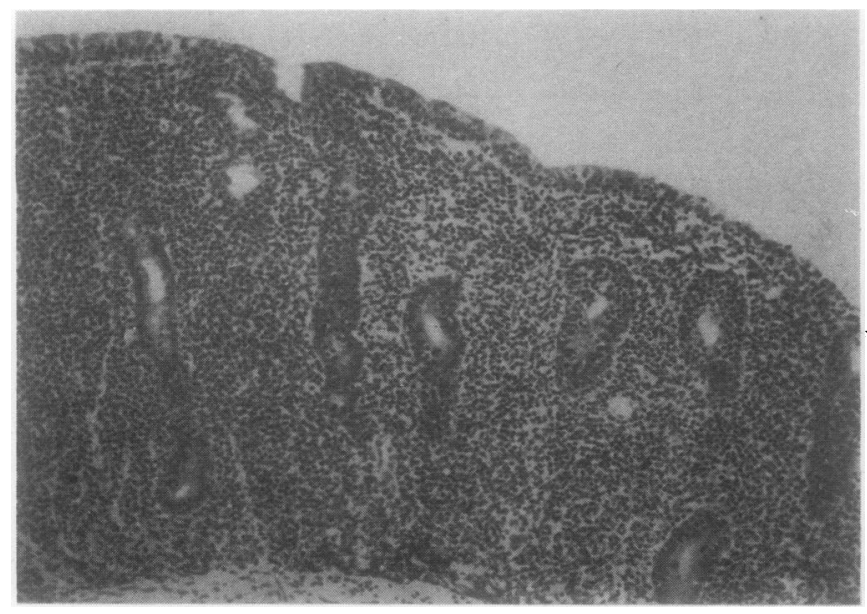

Fig. 2 "Pseudocoeliac" lesion with absent villi and crypt hypertrophy associated with diffuse lymphoma of centrocytic type showing widespread infiltration of epithelium and lamina propria. Low mitotic activity of epithelial lymphocytes excluded coexistent gluten-sensitivity. $\times 100$. 
months his symptoms recurred, he continued to lose weight and his haemoglobin fell to $10 \mathrm{~g} / \mathrm{dl}$.

At laparotomy (January, 1961) an annular constriction was found approximately $30 \mathrm{~cm}$ distal to the duodenal-jejunal flexure (Fig. 3 (a)) and resected; the tumour was thought at that time to be Hodgkin's disease ${ }^{25}$ and he received a total dose of 3000 rads to the whole abdomen over the next month. Ten months later, he complained of further generalised abdominal pain and vomiting. He was again thin and wasted with clubbing of the fingers. There was a megaloblastic anaemia with a normal serum $B_{12}$ and gross steatorrhoea (fat content $90 \%$ faecal weight; normal $<20 \%$ ). Serum proteins and barium examination were normal. Improvement was achieved with a low fat diet, supplemented with oral iron and folic acid.

Approximately 18 months later he again experienced episodes of lower abdominal pain, diarrhoea and $8 \mathrm{~kg}$ weight loss. Investigations revealed a haemoglobin of $9 \mathrm{~g} / \mathrm{dl}$; serum $\mathrm{Ca}^{++} 8 \cdot 5$ $\mathrm{mg} / 100 \mathrm{ml}$; serum albumin $35 \mathrm{~g} / \mathrm{l}$ and moderate steatorrhoea ( $36 \%$ dried weight). He was presumed to have mild radiation enteropathy, but despite nutritional supplements he continued to have episodic diarrhoea and was unable to work.

In February 1976 (aged 56 yr) he was seen at Hope Hospital on account of diarrhoea, although he had shown some subjective improvement over the years and had been able to carry out a light job. Significant investigations showed anaemia ( $\mathrm{Hb} 9.6 \mathrm{~g} / \mathrm{dl}$ ), hypoalbuminaemia $(26 \mathrm{~g} / \mathrm{l})$, steatorrhoea (faecal fat $40 \mathrm{~g} / 24 \mathrm{~h}$ ), a "flocculation pattern" on $x$-ray and a "flat" jejunal mucosa (Fig. 3b). The serum IgA concentration was grossly raised $(10 \mathrm{~g} / \mathrm{l}$, normal $0 \cdot 5$ $4.5 \mathrm{~g} / \mathrm{l})$. He was thought to have coeliac disease and started on a gluten-free diet. However, he failed to show any symptomatic response to this, and a jejunal
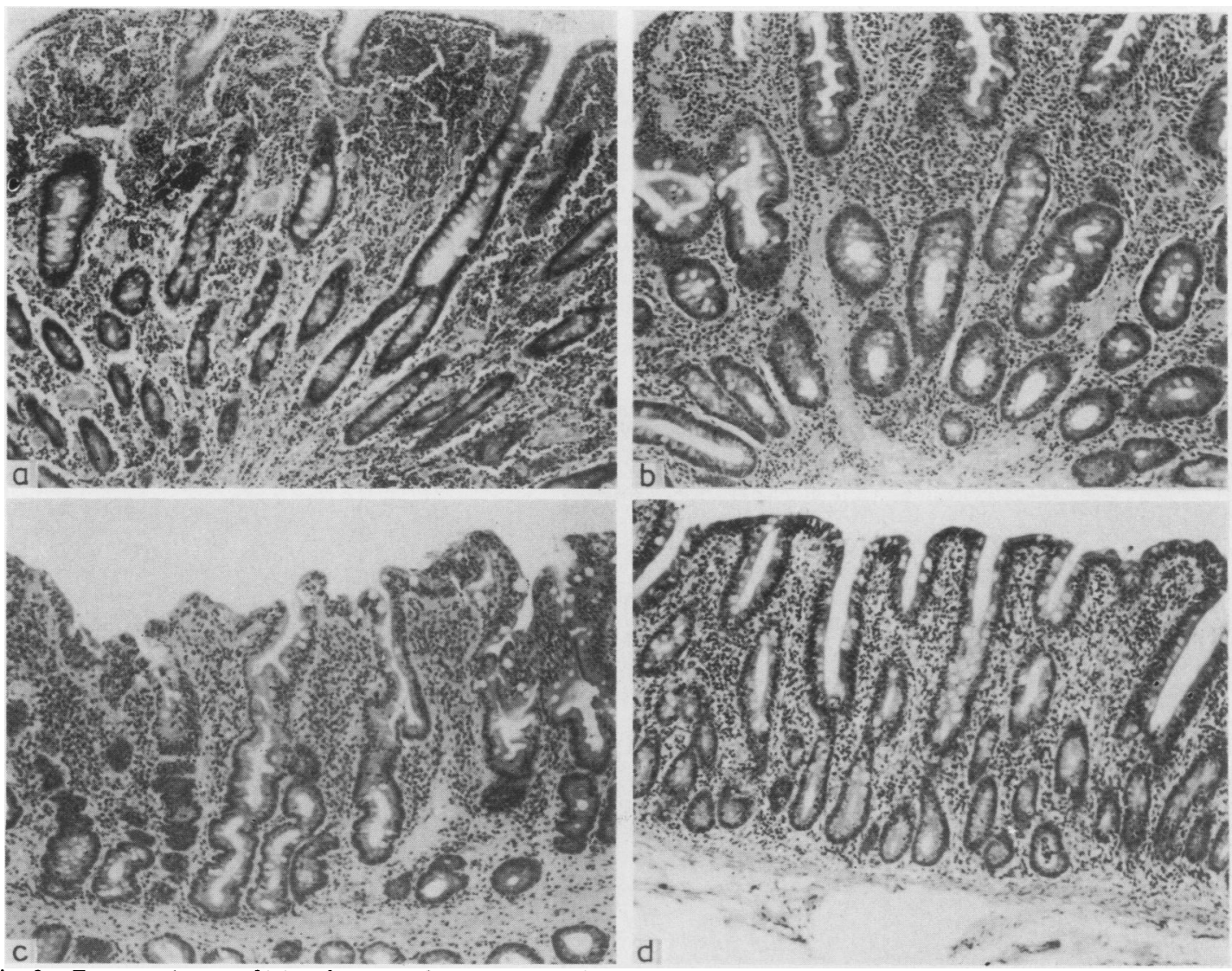

Fig. 3 Four specimens of jejunal mucosa from patient with terminal malignant histiocytosis. (a) at original presentation in 1961; (b) from specimen obtained in 1976 before a gluten-free diet and (c) 6 months after treatment and finally (d) at laparotomy in 1977. All specimens show a virtually flat mucosa with crypt hypertrophy; there is no apparent response to gluten restriction and mitotic activity of epithelial lymphocytes was not raised. $\times 80$. 
biopsy performed six months later was still abnormal (Fig. 3). Three months later he developed intestinal perforation, and at laparotomy the small bowel was thickened and inflamed. He died shortly after a second operation for perforation accompanied by internal fistulae.

\section{Comment}

This man's original illness was considered to be due to Hodgkin's disease. ${ }^{25}$ Thereafter he remained in poor health and developed radiation-induced malabsorption. Fifteen years later, he again presented with malabsorption associated with a "flat" jejunal mucosa although there was no symptomatic or morphological response to a gluten-free diet. Subsequently he died from "lymphoma" causing multiple perforations and fistulae throughout the small bowel. Review of the later surgical biopsies by the immunoperoxidase technique revealed malignant histiocytosis of intestine (Dr Peter Isaacson).

Mitotic indices of epithelial lymphocytes in the jejunal biopsy taken at the time of initial laparotomy in 1961 and in both peroral specimens (before and after GFD) were within normal limits (Table), suggesting that this man did not have coeliac disease, despite the type of tumour. ${ }^{2627}$ At his second laparotomy (1977) the intestinal mucosa was diffusely infiltrated with histiocytes which were also identified in bone marrow. There had clearly been no response of his mucosal lymphocytes to a GFD, the mitotic index being similar to that before dietary treatment commenced (Table).
CASE 4: INFANT, AGED 18 MONTHS

This boy developed recurrent attacks of otitis media, skin sepsis, sinusitis and pneumonia from the age of five months. Persistent diarrhoea began when he was fifteen months old, and investigations a few months later revealed panhypogammaglobulinaemia which was treated with intramuscular immunoglobulin injections at a dose of $50 \mathrm{mg} / \mathrm{kg} /$ week. Although satisfactory serum concentrations of IgG were $\vec{\circ}$ achieved $(>2 \mathrm{~g} / \mathrm{l})$ intermittent diarrhoea continued and he remained in poor health, both his height and weight were below the 3rd percentile.

Further investigations (at age $3 \mathrm{yr}$ ) revealed iron deficiency anaemia, low serum folate, low serum calcium, but normal serum albumin and alkaline phosphatase. Faecal fat was raised $(30 \mathrm{mmol} / 24 \mathrm{~h}$; $\vec{c}$ normal $<18 \mathrm{mmol} / 24 \mathrm{~h})$ and xylose absorption 을 reduced $(0.3 \mathrm{~g}$ of $5 \mathrm{~g}$ oral load after $5 \mathrm{~h}$; normal $>1.2$ g). No pathogens or Giardia organisms were seen on stool examinations. Jejunal biopsy was "flat" and contained scanty IgG cells only on direct immunofluorescence. Normal numbers of circulating B lymphocytes were present.

In view of his ill-health, malabsorption and "flat" mucosa despite adequate immunoglobulin replacement, he was started on a gluten-free diet without symptomatic improvement. Repeat jejunal biopsies performed 6 and 18 months later showed no morphological response and hence the diet was stopped. Treatment was then switched to regular plasma infusions, with subsequent improvement in well-being, a significant reduction in intestinal

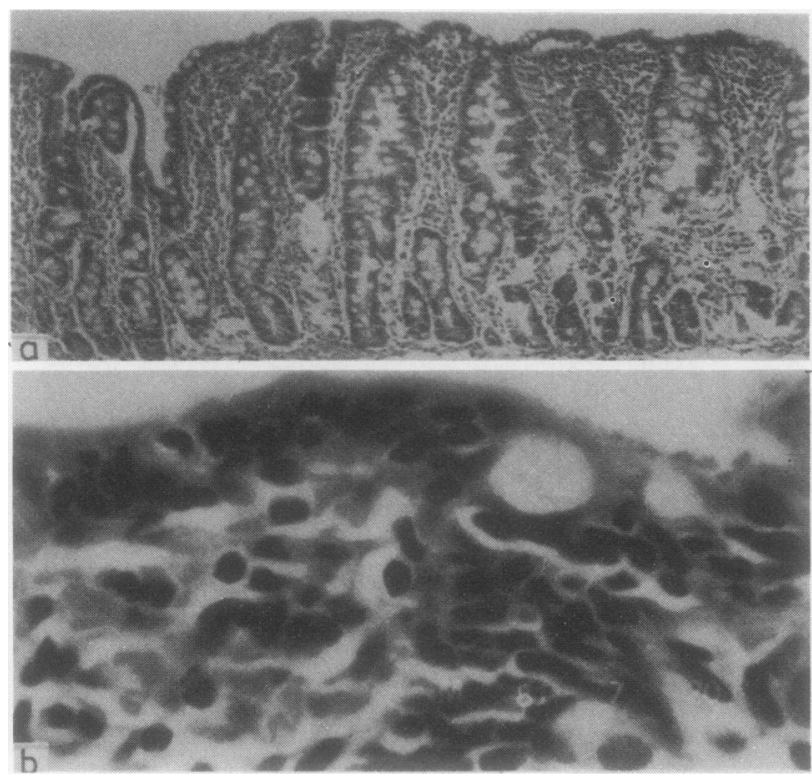

Fig. 4 (a) Flat jejunal mucosa (case 5) due to immunodeficiency. $\times 80$. (b) Detail shows small epithelial cells distorted by lymphocytes. $\times 320$. 
symptoms and a growth spurt above the 5th percentile.

\section{Comment}

This child had severe hypogammaglobulinaemia which is probably not sex-linked in view of the absent family history and the presence of circulating B-cells. This case illustrates that severe malabsorption accompanied by a "flat" mucosa is not necessarily due to gluten-sensitivity or necessarily likely to be responsive to a gluten-free diet. Review of his initial jejunal biopsy revealed a severe lesion, with small, abnormal epithelial cells. However, the mitotic index of interepithelial lymphocytes was normal (MI : zero). Such observations (if made at the time) could have predicted that this child was not glutensensitive, thereby avoiding the need for a prolonged trial of gluten restriction, and might have led to plasma infusions being instituted at an earlier stage.

\section{CASE 5: BOY, AGED 15 YR}

He presented with a three-year history of diarrhoea and steatorrhoea, but had not suffered unduly from other unusual or recurrent infections. Both his sisters and other family members were well. Investigations showed the following: haemoglobin $12 \cdot 3 \mathrm{~g} / \mathrm{dl}, \mathrm{MCV}$ $78 \mathrm{fl}$, serum iron $4.6 \mathrm{mmol} / \mathrm{l}$. Serum folate, $\mathrm{B}_{12}$, albumin, $\mathrm{Ca}, \mathrm{P}$, and alkaline phosphatase were normal. There was steatorrhoea (faecal fat $63 \mathrm{mmol} /$ $24 \mathrm{~h}$; normal $<20 \mathrm{mmol} / 24 \mathrm{~h}$ ) and mild xylose malabsorption. Culture of jejunal aspirate produced a moderate growth of Streptococcus viridans but no other significant pathogens. Barium follow-through examination showed a malabsorption pattern, and a jejunal biopsy was "flat" (Fig. 4), with scanty Igcontaining cells on direct immunofluorescence. There was marked panhypogammaglobulinaemia, but assessment of cell-mediated immunity was normal.

Rapid improvement followed intramuscular injections of immunoglobulin $(25 \mathrm{mg} / \mathrm{kg} /$ week $)$ and oral cotrimoxazole. Reassessment one year later showed normal xylose absorption and a normal daily faecal fat output (18 mmol/24 h); furthermore, a repeat jejunal biopsy showed return of villous morphology.

\section{Comment}

This patient had common variable immunodeficiency of adult onset, with complete resolution of the associated malabsorption syndrome with antibiotic and immunoglobulin injections. Mitotic indices of epithelial lymphocytes were not raised before receiving a gluten-free diet (Table), thus confirming that he was not gluten-sensitive.
CASE 6: GIRL, AGED 18 YR

Although this girl had suffered recurrent upper respiratory tract infections from the age of three years, Haemophilus influenzae meningitis when aged $12 \mathrm{yr}$, lobar pneumonia when $14 \mathrm{yr}$, and pneumococcal meningitis when aged $17 \mathrm{yr}$, major investigation began with the onset of persistent diarrhoea. This was initially thought to be "nonspecific colitis" and was treated with Salazopyrine (sulphasalazine) and codeine phosphate. Later investigations revealed the presence of severe steatorrhoea (faecal fat output $27 \mathrm{~g} / 24 \mathrm{~h}$ ), impaired xylose absorption, and low serum calcium and high phosphatase activities suggestive of osteomalacia. Barium follow-through examination of small intestine showed a "malabsorption pattern", but attempts to secure a jejunal biopsy failed. She was treated with a gluten-free diet without symptomatic improvement.

Six months later when reinvestigated after a severe pulmonary infection, hypogammaglobulinaemia was found and replacement immunoglobulin injections $(25 \mathrm{mg} / \mathrm{kg} / \mathrm{week})$ were commenced. Other results showed anaemia (Hb 10.2 g/dl), iron deficiency (serum $4 \mathrm{mmol} / \mathrm{l})$, folate deficiency $(1 \cdot 1 \mu \mathrm{g} / \mathrm{l}$, hypocalcaemia $(2.02 \mathrm{mmol} / \mathrm{l})$, hypophosphataemia $(0.72 \mathrm{mmol} / \mathrm{l})$ and raised alkaline phosphatase $(224$ IU/l). There was steatorrhoea (faecal fat $42 \mathrm{mmol} / 24$ h), xylose malabsorption and excess protein loss (5.4\% of injected ${ }^{51} \mathrm{Cr}$; normal $<1 \%$ in 5 days). Jejunal biopsy revealed a "flat" lesion, the lamina propria containing no plasma cells on direct immunofluorescence. Culture of the jejunal fluid produced a heavy growth of Streptococcus faecalis, but no Giardia organisms were seen.

A gluten-free diet was therefore restarted; her weight remained static although there was some improvement in diarrhoea. One year later (aged 19 yr) there was still gross steatorrhoea $(38 \mathrm{mmol} / 24 \mathrm{~h})$, xylose malabsorption, Escherichia coli present in jejunal fluid and a "flat" mucosa. The diet was stopped and a dramatic improvement was achieved with lincomycin, nystatin and metronidazole.

\section{Comment}

It is clear that the major cause of this girl's malabsorption and weight loss was common variable immunodeficiency of adult onset, with bacterial overgrowth of the upper jejunum which responded promptly to appropriate antibiotic therapy. Attempts to induce remission with a gluten-free diet failed on two separate occasions. The mitotic index in the jejunal biopsy was not raised $(\mathrm{MI}=$ zero). Thus, a confident prediction could have been made that she did not have coexistent coeliac disease, and an 

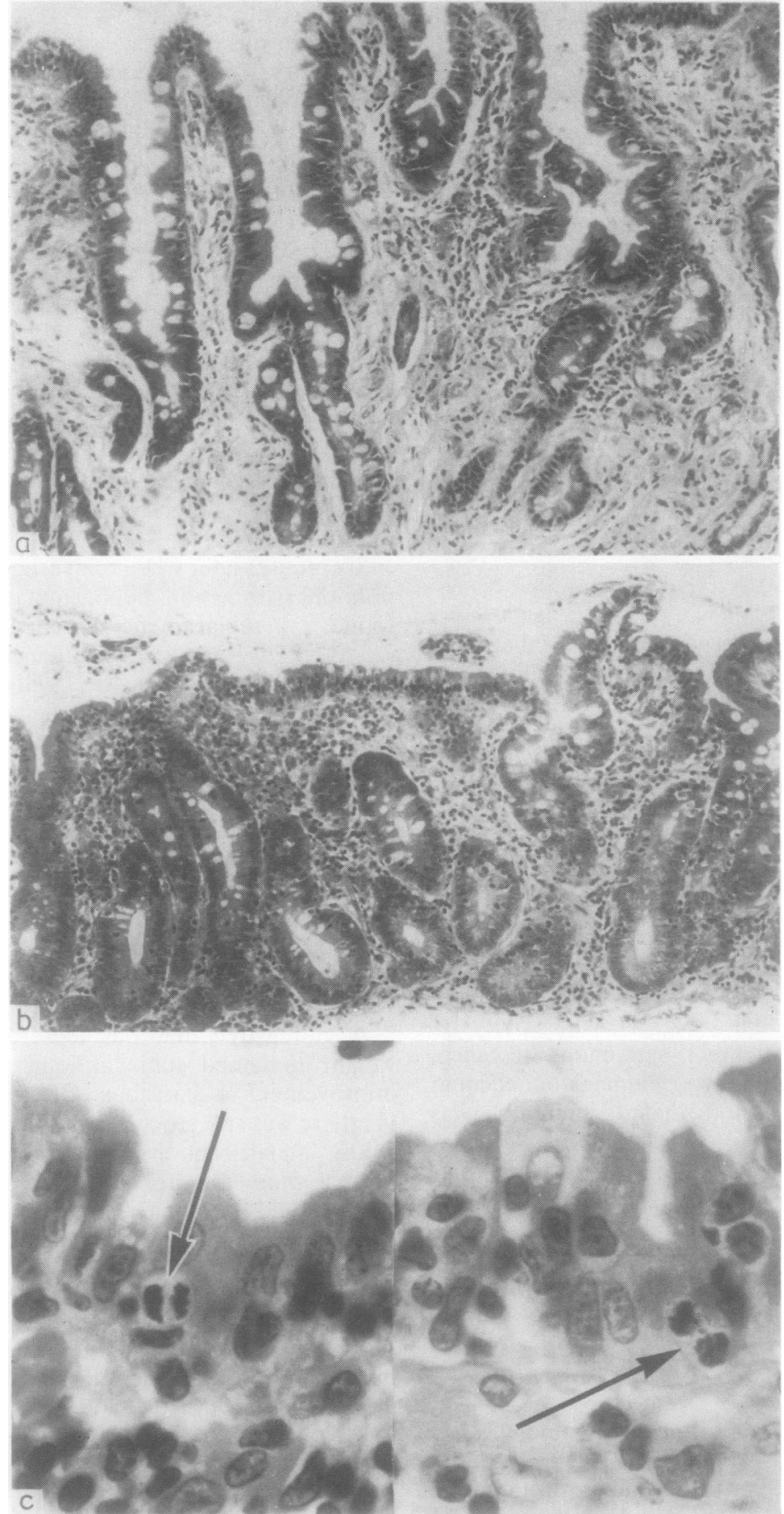

Fig. 5 Case 7 (combined immunodeficiency and coeliac disease). Upper panel (a) demonstrates villous regeneration after gluten restriction. $\times 160$. Central panel (b) shows deterioration and return to severe lesion after gluten ingestion. $\times 80$. (c) Mitotic figures in epithelial lymphocytes (arrows) of latter specimen are shown in detail. $\times 1000$. 
unnecessary trial of a gluten-free diet could therefore have been avoided.

\section{CASE 7: MAN, AGED 63 YR}

Hypogammaglobulinaemia had been diagnosed 10 years previously following episodes of pneumonia and recurrent upper respiratory tract infections. He had remained virtually asymptomatic on regular weekly injections of immunoglobulin.

When aged $63 \mathrm{yr}$, he developed diarrhoea up to four times daily, with mild steatorrhoea (faecal fat 9 $\mathrm{g} / 24 \mathrm{~h}$; normal $<6$ ). There was macrocytosis due to folate deficiency (red cell folate $76 \mathrm{ng} / \mathrm{ml}$; normal > $120 \mathrm{ng} / \mathrm{ml}$ ). Barium follow-through examination showed malabsorption pattern suggesting nodular lymphoid hyperplasia. He was not achlorhydric, and pancreatic tryptic activity (Lundh test meal) was normal. There was no appreciable small bowel bacterial colonisation. A jejunal biopsy revealed a "flat" lesion with considerable distortion of the surface epithelium.

In view of these findings, he was started on a gluten-free diet to which he made a rapid response and six months later, a repeat biopsy of his small intestinal mucosa showed regeneration of villi (Fig. 5) although no plasma cells were identifiable within the lamina propria. Approximately two years later he was challenged with $20 \mathrm{~g}$ gluten; no significant change was seen in mucosal morphology 21 hours later and neither was there any evidence of serum complement consumption. It was concluded that the patient was not gluten-sensitive, and he was allowed a normal diet. Three months later he returned with diarrhoea, steatorrhoea and $4 \mathrm{~kg}$ weight loss. A further biopsy of jejunum (Fig. 5) now revealed marked deterioration with complete villous flattening and disruption of the epithelial cell layer. A gluten-free diet was again introduced, since when he has remained in good health. ${ }^{28}$

\section{Comment}

This man had late onset, severe hypogammaglobulinaemia coexistent with proven coeliac disease. It is pertinent that a conventional gluten challenge failed to demonstrate his susceptibility, such that his gluten-free diet was stopped. Undoubted proof of his sensitivity became manifest within three months, with the recurrence of diarrhoea, and the development of a severe lesion of upper jejunal mucosa accompanied by a striking increase in mitotic activity of epithelial lymphocytes (Fig. 5).

The four specimens of jejunum that were available for blind review revealed high mitotic indices at presentation $(0.43 \%)$ and after recurrence of symptoms on a normal diet $(0 \cdot 66 \%)$. During the period of gluten-restriction, mitotic indices fell within the normal range $(0 \cdot 1 \%)$ (Table). In this case, confirmation of diagnosis required three years observation; analysis of mitotic indices in the initial jejunal specimen, however, could have provided objective evidence of his gluten-sensitivity, and hence of the need for life-long dietary gluten restriction.

\section{Discussion}

More than 30 clinical and experimental causes of villous "flattening" are now recognised. ${ }^{7}$ Since a "flat" mucosa reflects a non-specific response to various pathological agents and is not necessarily gluten-induced, both the clinical definition and diagnosis of coeliac disease depend on the demonstration of morphological improvement following a gluten-free diet. While this criterion admittedly permits (retrospectively) the diagnosis of most coeliac patients, the definition falters in the face of certain paradoxical observations. For example, even in the earliest studies there were hints of poor morphological responses in patients in whom dietary default could not be reasonably blamed; the argument that poor dietary control is responsible for all "non-responders" is not always valid, ${ }^{29}$ since many of these patients are known to adhere rigidly to their diet. Neither is scrupulous adherence to the diet a prime necessity for improvement, since good mucosal responses are often seen in patients whose approach to gluten restriction is somewhat more casual. Moreover, other well-documented cases have been described where initial morphological responsiveness was subsequently lost after inadvertent or unsuspected ingestion of gluten. ${ }^{893031}$ Is it reasonable to suppose that such patients are not gluten-sensitive, and if not, to what is their condition due? Certainly, in terms of other possible dietary agents, very few causes of prolonged pseudocoeliac syndromes, other than soy protein ${ }^{32}$ and fish/poultry sensitivity, ${ }^{33}$ have been described.

Many attempts have been made to understand more fully the pathophysiology of coeliac disease and to uncover a reliable diagnostic test which permits confident recognition of all gluten-sensitive individuals. In recent years, attention has swung away from the possibility of a primary enzyme defect within the epithelial cell $^{34}$ towards an immunological mechanism of gluten-induced mucosal damage. However, immunological tests based on immunoglobulin-isotope distribution within the lamina propria, ${ }^{35-37}$ levels of circulating antigluten antibody, ${ }^{38} 39$ skin testing with gluten subfractions, ${ }^{4041}$ levels of reticulin antibody, ${ }^{4243}$ in vitro synthesis of antigluten antibody by jejunal mucosal in 
organ culture ${ }^{44}$ and even histocompatibility testing, ${ }^{45-47}$ fail to provide clear-cut distinctions from control individuals or patients with other intestinal diseases. $^{7}$

The subject (case 7) originally reported by Webster and colleagues ${ }^{28}$ is of great theoretical importance in showing that coeliac disease, with mucosal flattening and epithelial cell damage, and subsequent mucosal regeneration after gluten withdrawal can occur even in the presence of profound antibody deficiency. The absence of complement activation in this patient after acute gluten-challenge suggests that the essential pathogenesis of coeliac disease is independent of antigen-antibody complex formation within the lamina propria or along the epithelial basement membrane ${ }^{1}$ at least in this patient. Furthermore, the immune defect makes it unlikely that the high rate of loss of epithelial cells with consequent hypertrophy of the glandular crypts was mediated by an antibodydependent cell-mediated cytotoxic mechanism. ${ }^{48}$ Although this and other patients with variable immunodeficiency do have occasional immunoglobulin-containing cells within the lamina propria of the intestine the possibility, albeit remote, that antibody-mediated mechanisms may induce mucosal damage cannot therefore be totally ruled out.

On the other hand, it is much more reasonable to believe that the fundamental abnormality in coeliac disease involves a local cell-mediated reaction to gluten, or a subunit thereof, in individuals predisposed by certain HLA-D(R)-related genes. In this context, much attention in recent years ${ }^{49-51}$ has been paid to the apparent lymphocytic "infiltration" within the epithelium of untreated coeliac mucosae, a notion that has come to be widely held as an essential, if not diagnostic, histological characteristic of a local, gluten-induced reaction within the mucosa. However, a more critical evaluation of the data upon which this view is based seriously challenges its dogma-like status: ${ }^{7}$

Firstly, control "normal" mucosae from noncoeliac patients have been used as a basis for comparing changes in epithelial lymphocyte populations, and few investigators have studied "flat" mucosae from other disease-control patients (lymphoma, immunodeficiency, Crohn's disease, heavy-chain disease and so on) where lymphocytes populations may also be changed, ${ }^{23}$ thus weakening the claim that the presumed "infiltrate" is wholly, or specifically, gluten-induced.

Secondly, and more importantly, these data are suspect because the quantitative method employed compares one variable (lymphocyte numbers) with another (length of epithelium or arbitrary number of epithelial cells). The validity of this approach is suspect in view of the fact that "flat" mucosae obviously have a much reduced surface area, such that the total number of epithelial cells required for coverage may be reduced by as much as $75 \%$ from normal. ${ }^{52}$ The flaw in this widely-used method of relating lymphocyte numbers to a fixed amount of epithelium has been exposed recently in two, independent studies employing controlled, morphometric analyses; ${ }^{2053}$ in both, no increase in lymphocyte numbers between control and coeliac mucosae could be detected.

Little is known about cell-mediated reactions within the intestinal tract, ${ }^{5455}$ but the view that a similar mechanism underlies the pathogenesis of coeliac disease is strengthened by the following observations: (i) that villous flattening in animals carrying intestinal worms, ${ }^{5657}$ or subjected to a graftversus-host reaction ${ }^{58}$ or allograft rejection ${ }^{5960}$ is $\mathrm{T}$ lymphocyte dependent; (ii) that lymphokine production (migration inhibition factor) occurs during culture of untreated whole-mucosa in vitro ${ }^{61}$ although the cell(s) responsible have not been identified; and (iii) that in untreated coeliac mucosa a significant population of blast-transformed and highly mitotic, lymphocytes is present within the interepithelial cell spaces. ${ }^{72021}$ These latter changes revert to normal with gluten restriction, indicating that some lymphocytes circulating within the epithelial pool could be responding to luminal antigen (gluten) to which they were previously sensitised, as suggested by earlier studies on the ultrastructure and kinetics of interepithelial spacelymphocytes. ${ }^{62} 63$

Moreover, additional observations have clearly shown that a raised mitotic index among epithelial lymphocytes is virtually exclusive to coeliac disease alone,,$^{372122}$ and this paper illustrates the use of this highly discriminatory test in circumstances especially likely to cause diagnostic problems.

Reporting of "flat" jejunal biopsy specimens in terms of a mitotic index of epithelial lymphocytes 0 could also be adopted as a routine, yet objective, way of interpreting what is otherwise an extremely non- 음 specific morphological response to a wide variety of $\frac{\vec{N}}{\mathrm{~N}}$ pathological stimuli. ${ }^{22}$ Such a diagnostic test for $\Omega$ coeliac disease, unlike all others employed or $\tilde{O}$ proposed hitherto, is not particularly time- N consuming, and more importantly, requires no expensive equipment, elaborate technique or special expertise. A low mitotic index $(<0.2 \%)$ has been $\frac{C}{\Phi}$ shown in this study (i) to exclude coeliac disease as a $\stackrel{?}{?}$ presumptive cause of villous flattening and (ii) render 0 a prospective trial of gluten-free diet unnecessary. A low mitotic index also appears to be helpful in $\stackrel{\odot}{\overparen{D}}$ distinguishing primary intestinal lymphomas (cases $2 \overrightarrow{\mathbb{D}}$ and 3) from those coexisting with gluten-sensitivity, of which the majority are histiocytic. ${ }^{2627}$ 
However, it is not certain that all histiocytic tumours of the intestine, or their associated villous flattening, are necessarily due to gluten-sensitivity. For example, presumed histiocytic tumours of je junum have been reported in Japan ${ }^{64}$ and in Iran, ${ }^{65}$ in which countries coeliac disease is rarely, if ever, seen. In addition to our case 2 above, we have also found a low mitotic index in a case of malignant histiocytosis published by Isaacson and his colleagues. ${ }^{66}$ Their patient (case 2) was iron-deficient, but this is not acceptable evidence for a diagnosis of coeliac disease, especially when required to support the view held by these authors ${ }^{66}$ that villous flattening is the result of gluten-sensitivity, rather than to the tumour proliferation per se.

Clearly, further studies of larger series of malignant histiocytosis of the intestine are needed to resolve this viewpoint.

\section{References}

' Booth CC, Peters TJ, Doe WF. Immunology of the gut. Ciba Foundation Symposium 46 (New Series). Elsevier/North Holland: Ciba Found Symp 1977;46 (new series):329.

${ }^{2}$ Strober W. In: McNicholl B, McCarthy CF, Fottrell P, eds. Perspectives in coeliac disease. Lancaster: MTP, 1978:169.

${ }^{3}$ Marsh MN. The small intestine: mechanisms of local immunity and gluten sensitivity. Clin Sci Mol Med 1981;61:497-503.

+ Booth CC. Enterocyte in coeliac disease. Br Med J 1970;iii:72531.

${ }^{5}$ Rubin CE, Eidelman S, Weinstein WM. Sprue by any other name. Gastroenterology 1970;58:409-13.

- Creamer B. The small intestine. London: Heinemann, 1974:91.

${ }^{7}$ Marsh MN. Studies of intestinal lymphoid tissue-V: The cytology and electron microscopy of gluten-sensitive enteropathy, with particular reference to its immunopathology. Scand J Gastroenterol 1981;16 (suppl 70):87-106.

${ }^{8}$ Neale G. A case of coeliac disease resistant to treatment. Br Med J 1968;ii:678-84.

' Dowling RH, Henry K. Non-responsive coeliac disease. Br Med J 1972;iii:624-31.

${ }^{10}$ Meuwisse G. Diagnostic criteria in coeliac disease. Acta Paediatr Scand 1970;59:461-3.

"Visakorpi JK. An international inquiry concerning the diagnostic criteria of coeliac disease. Acta Paediatr Scand 1970;59:463-4.

${ }^{12}$ Schmerling DH. An analysis of controlled relapses in gluteninduced coeliac disease. Acta Paediatr Scand 1969;58:311.

${ }^{13}$ Young WF, Pringle EM. 110 children with coeliac disease, 19501969. Arch Dis Child 1971;46:421-36.

${ }^{14}$ Hamilton JR, McNeill LK. Childhood coeliac disease: response of treated patients to a small uniform daily dose of wheat gluten. J Pediatr 1972;81:885-93.

is Packer S, Charlton V, Keching J, et al. Gluten challenge in treated coeliac disease. Arch Dis Child 1978;53:449-55.

${ }^{10}$ Kumar P, O'Donoghue DP, Stenson K, Dawson AM. Reintroduction of gluten in adults and children with treated coeliac disease. Gut 1979;20:743-9.

${ }^{17}$ Egan-Mitchell B, Fottrell PF, McNicholl B. In: McNicholl B, McCarthy CF, Fottrell PF, eds. Perspectives in coeliac disease. Lancaster: MTP, 1978:251.

${ }^{18}$ Scmitz J, Jos J, Rey J. In: McNicholl B, McCarthy CF, Fottrell PF, eds. Perspectives in coeliac disease. Lancaster: MTP, 1978:259.

${ }^{19}$ Marsh MN. Morphology and cellular kinetics of epithelial lymphocytes in coeliac disease: a re-appraisal of the jejunal lesion. Gut 1979;20:909.
${ }^{20}$ Marsh MN. Studies of intestinal lymphoid tissue-III: Quantitative analyses of epithelial lymphocytes in the small intestine of human control subjects and of patients with coeliac sprue. Gastroenterology 1980;79:481-92.

${ }^{21}$ Marsh MN. Abnormal behaviour of epithelial lymphocytes in sprue. Gastroenterology 1980;78:1218.

${ }^{22}$ Marsh MN. Studies of intestinal lymphoid tissue. IV-The predictive value of raised mitotic indices among jejunal epithelial lymphocytes in the diagnosis of gluten-sensitive enteropathy. J Clin Pathol 1982;35:517-25.

${ }^{2.3}$ Marsh MN. Epithelial lymphocytes in coeliac sprue. Gastroenterology. 1981;80:1086-7.

${ }^{24}$ Cooke WT, Smith WT. Neurological disorders associated with adult coeliac disease. Brain 1966;89:683-721.

${ }^{25}$ Williams EI. Hodgkin's disease arising primarily in the jejunum. Br Med J 1962;i: 158 .

${ }^{26}$ Freeman HJ, Weinstein WM, Shnitka TK, Piercy JR, Wensel RH. Primary abdominal lymphoma. Am J Med 1977;63:585-94.

${ }^{27}$ Isaacson P, Wright DH. Malignant histiocytosis of the intestine. Hum Pathol 1978;9:661-77.

${ }^{28}$ Webster ADB, Slavin G, Shiner M, Platts-Mills T, Asherson GL. Coeliac disease with severe hypogammaglobulinaemia. Gut 1981;22:153-7.

${ }^{29}$ Cooke WT, Asquith P. Introduction and definition. In: Clinics in gastroenterology (coeliac disease). Vol 3. London: Saunders, 1974:3.

${ }^{30}$ Doe WF, Evans D, Hobbs J, Booth CC. Coeliac disease, vasculitis and cryoglobulinaemia. Gut 1972;13:112-23.

${ }^{31}$ Jones PE, Peters TJ. Oral zinc supplements in non-responsive coeliac syndrome: effect on jejunal morphology, enterocyte production, and brush border disaccharidase activities. Gut 1981;22:194-8.

${ }^{32}$ Ament ME, Rubin CE. Soy protein-another cause of the flat intestinal lesion. Gastroenterology 1972;62:227-34.

${ }^{33}$ Baker A, Rosenberg I. Refractory sprue: recovery after removal of non-gluten dietary proteins. Ann Intern Med 1978;89:505-8.

${ }^{34}$ Frazer AC. The malabsorption syndrome with special reference to the effects of wheat gluten. Adv Clin Chem 1962;5:69-106.

${ }^{35}$ Douglas AP, Crabbe PA, Hobbs JR. Immunochemical studies on the serum, intestinal secretions and intestinal mucosa in patients with adult coeliac disease and other forms of coeliac syndrome. Gastroenterology 1970;59:414-25.

${ }^{36}$ Pettingale KW. Immunoglobulin-containing cells in the coeliac syndrome. Gut 1971;12:291-6.

${ }^{37}$ Lancaster-Smith M, Kumar P, Marks R, Clark ML, Dawson AM. Jejunal mucosal immunoglobulin-containing cells and jejunal fluid immunoglobulins in adult coeliac disease and dermatitis herpetiformis. Gut 1974;15:371-6.

${ }^{38}$ Kenrick JG, Walker-Smith J. Immunoglobulins and dietary antibodies in childhood coeliac disease. Gut 1970;11:635-40.

${ }^{39}$ Alarcon-Segovia D, Herskovic T, Wakim KG, Green DA, Scudamore $\mathrm{HH}$. Presence of circulating antibodies to gluten and milk fractions in patients with non-tropical sprue. Am J Med 1964;36:485-99.

${ }^{4}$ Baker PG, Read AE. Positive skin reactions to gluten in coeliac disease. $Q J$ Med 1976;45:603-10.

${ }^{4}$ Anand BS, Truelove SC. Skin test for coeliac disease using a subfraction of gluten. Lancet 1977; ;:118-20.

${ }^{42}$ Magalhaes AF, Peters TJ, Doe WF. Studies on the nature and significance of connective tissue antibodies in adult coeliac disease and Crohn's disease. Gut 1974;15:284-8.

${ }^{43}$ Stevens F, Lloyd R, Egan-Mitchell B, et al. Reticulin antibodies in patients with coeliac disease and their relatives. Gut 1975;16:598-602.

${ }^{44}$ Falchuk ZM, Strober W. Gluten-sensitive enteropathy: synthesis of antigliadin antibody in vitro. Gut 1974;15:947-52.

${ }^{45}$ Falchuck ZM, Rogentine GN, Strober W. Predominance of histocompatibility antigen HLA-8 in patients with glutensensitive enteropathy. J Clin Invest 1972;51:1602-5.

${ }^{46}$ Stokes PL, Asquith P, Holmes GK, Mackintosh P, Cooke WT. 
Histocompatibility antigens associated with adult coeliac disease. Lancet 1972;ii:162-4.

${ }^{47}$ Keuning J, Pena AS, van Leeuwen A, van Hooff JP, van Rood J. HLA-DW3 association with coeliac disease. Lancet 1976; i:5067.

${ }^{48}$ Ezeoke A, Ferguson N, Fakhwi O, Hekkins W, Hobbs JR. In: Hekkins W, Pena AS, eds. Coeliac disease. London: Stenfertkroise, 1974:176.

${ }^{49}$ Ferguson A and Murray D. Quantitation of intraepithelial lymphocytes in human jejunum. Gut 1971;12:988-94.

${ }^{\text {so }}$ Fry L, Seah P, McMinn R, Hoffbrand AV. Lymphocytic infiltration of epithelium in diagnosis of gluten-sensitive enteropathy. Br Med J 1972;iii:371-4.

51 Holmes GK, Asquith P, Stokes P, Cooke WT. Cellular infiltration of jejunal biopsies in adult coeliac disease in relation to gluten withdrawal. Gut 1974;15:278-83.

52 Creamer B. The turnover of the epithelium of the small intestine. Br Med Bull 1967;23:226-30.

${ }^{53}$ Guix M, Skinner JM, Whitehead R. Measuring intraepithelial lymphocytes, surface area, and volume of lamina propria in the jejunal mucosa of coeliac patients. Gut 1979;20:275-8.

${ }^{54}$ Glaister JR. Some effects of oral administration of oxazolone to mice. Int Arch Allergy Appl Immunol 1973;45:828-43.

${ }^{55}$ Frederick GT, Bohl EH. Local and systemic cell-mediated immunity against transmissible gastroenteritis and intestinal viral infection of swine. J Immunol 1976;116:1000-4.

${ }^{56}$ Ferguson A, Jarrett EE. Hypersensitivity reactions in the small intestine. I. Thymus dependence of experimental "partial villous atrophy." Gut 1975;16:114-7.

${ }^{57}$ Manson-Smith DF, Bruce RG, Parrott DMV. Villous atrophy and expulsion of intestinal Trichinella spiralis are mediated by $T$ cells. Cell Immunol 1979;47:285-92.
${ }^{58}$ Reilly RW, Kirsner JB. Runt intestinal disease. Lab lnvest 1965;14:102-7.

${ }^{59}$ MacDonald TT, Ferguson A. Effects of allograft rejection on mucosal architecture and lymphoid cell infiltrate. Gut 1976;17:81-91.

${ }^{60}$ MacDonald TT, Ferguson A. The effects of allograft rejection and graft-versus-host disease on epithelial cell kinetics. Cell Tissue Kinet 1977;10:301-12.

${ }^{61}$ Ferguson A, McClure J, MacDonald TT, Holden R. Cellmediated immunity to gliadin within the small intestinal mucosa in coeliac disease. Lancet $1975 ; \mathrm{i}: 985-7$.

${ }^{62}$ Marsh MN. Studies of intestinal lymphoid tissue-I: Electron microscopic evidence of "blast-transformation" in epithelial lymphocytes of mouse small intestinal mucosa. Gut 1975; 16:665-74.

${ }^{63}$ Marsh MN. Studies of intestinal lymphoid tissue-II: Aspects of proliferation and migration of epithelial lymphocytes in murine small intestine. Gut 1975;16:674-82.

${ }^{64}$ Aozasa K. Villous atrophy with crypt hyperplasia in malignant histiocytosis of the nose. J Clin Pathol 1982;35:606-10.

${ }^{65}$ Nasr K, Haghighi P, Bakhshandeh K, Haghshenas M. Primary lymphoma of the upper small intestine. Gut 1970;11:673-8.

${ }^{66}$ Isaacson P, Jones D, Sworn M, Wright D. Malignant histiocytosis of the intestine: report of three cases with immunological and cytochemical analysis. J Clin Pathol 1982;35:510-6.

Requests for reprints to: Dr MN Marsh, University Department of Medicine, Clinical Sciences Building, Hope Hospital, Eccles Old Road, Salford M6 8HD, Manchester, England. 